\title{
Nonestrogen-Dependent Malignant Neoplasm
}

National Cancer Institute

\section{Source}

National Cancer Institute. Nonestrogen-Dependent Malignant Neoplasm. NCI

Thesaurus. Code C46080.

Cancer that is not dependent upon the presence of estrogen for metastasis or growth. 2005 